\title{
Cheetah mothers' vigilance: looking out for prey or for predators?
}

\author{
T.M. Caro \\ Sub-Department of Animal Behaviour, University of Cambridge, Madingley, Cambridge CB3 8AA, UK, and \\ Serengeti Wildlife Research Institute, P.O. Box 661, Arusha, Tanzania \\ Received August 19, 1986 / Accepted January 8, 1987
}

Summary. Free-living cheetah (Acinonyx jubatus) cubs are killed by a number of predators, thus vigilance in cheetah mothers may be a form of anti-predator behaviour as well as a means of 10cating prey. Mothers' vigilance during the day was closely associated with measures of hunting but not with measures of anti-predator behaviour. In contrast, mothers' vigilance at kills was not related to hunting but was related to anti-predator behaviour. Both forms of vigilance decreased as cubs grew older. Vigilance during the day increased with litter size which supports a model of 'shared' parental investment (Lazarus and Inglis 1986) because after prey had been located and caught by mothers, cubs shared the prey between them. Vigilance at kills did not increase with litter size when cubs were young; in these situations predators stole cheetahs' prey and rarely chased cubs so, at most, only a single cub would be taken. Mothers' anti-predator behaviour away from kills did increase with litter size at young cub ages however; more cubs are killed in these circumstances the greater is the size of the litter. When cubs were older and could outrun predators, neither vigilance at kills nor anti-predator behaviour increased with litter size. These results strongly support two models of 'unshared' investment (Lazarus and Inglis 1986) and demonstrate, not only that superficially similar behaviour has different functions in different contexts, but that parental investment is shaped by the type of benefits accrued from it.

\section{Introduction}

Prey animals are assumed to be vigilant so as to detect predators (e.g. Bertram 1980; Dunbar and

Offprint requests to: Evolution and Human Behavior Program, Rackham Building, University of Michigan, Ann Arbor, MI 48109, USA
Dunbar 1980), while predators are considered to look up so as to locate prey (see Leyhausen 1979). These stereotypes ignore the facts that prey animals may monitor their environment for a variety of reasons (Lazarus and Inglis 1978), and that carnivores suffer competition from other predators (e.g. Kruuk 1972; Lamprecht 1978), are subject to high mortality due to intraspecific combat over mates and access to territories (e.g. Packer and Pusey 1982; Caro and Collins 1986; see Iwago 1986 for a dramatic photograph), are killed and eaten by other carnivores (references in Schaller 1967), and are relentlessly slaughtered by members of both traditional (e.g. Lienhardt 1961) and colonial societies (e.g. Best et al. 1962). Vigilance behaviour in carnivores may therefore not only be a means by which they scout for prey, as is commonly supposed, but is likely also to be a form of anti-predator behaviour.

Cheetahs (Acinonyx jubatus) are adversely affected by the activities of carnivores (see Myers 1975; McVittie 1979). Their kills are stolen by lions (Panthera leo), spotted hyaenas (Crocuta crocuta) and leopards (Panthera pardus) (13\% recalculated from Schaller 1972; 'nearly 10\%', Frame and Frame 1977), and both adults and cubs are killed by these predators (see Discussion for references). Burney (1980) reported 21 out of 22 cubs dying between 0 and 3 months of age in the Masai-Mara Game Reserve in Kenya, 14 of these due to other carnivores. Such reports suggest that cheetah mothers will be under strong selection to detect sources of danger as early as possible and to defend their cubs if necessary, because the consequences of failing to do so will dramatically lower their reproductive success. In support of this, Frame and Frame (1976) describe the extreme caution and vigilance shown by mothers returning to their dens.

If vigilance, defined as an animal visually monitoring its surroundings, is primarily a prelude to 


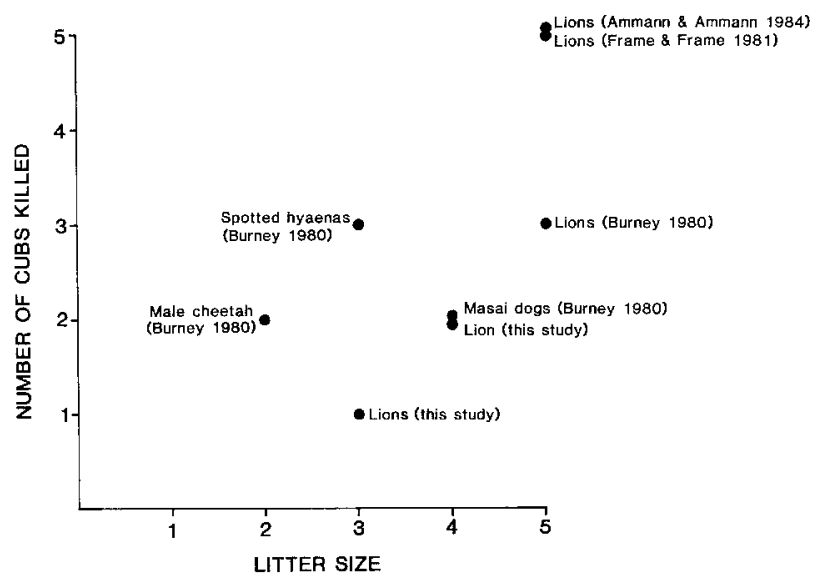

Fig. 1. Recorded instances of predation on 0-3 month old cheetah cubs in East Africa. Burney (1980) saw lions take 3 out of 5 13-day old cubs (the remaining 2 were apparently killed and eaten by lions overnight); spotted hyaenas took all 3 small cubs from a litter; a male cheetah may have taken both cubs from a litter of 2 before their eyes opened; and Masai dogs may have killed 2 out of a litter of 43 -month old cubs. Both Frame and Frame (1981) and Ammann and Ammann (1984) have evidence that lions killed all 5 members of 2 different litters of 4-week old cubs or less. Caro (this study) saw lionesses take 1 cub from a litter of 3 , and 2 from a litter of $4,1 \frac{1}{2}$-month old cubs in both cases $\left(n=8, r_{\mathrm{s}}=0.712, P<0.05\right)$.

hunting however, it is a form of 'shared' parental investment (sensu Lazarus and Inglis 1986) although the costs of this activity in terms of future reproduction and survival are admittedly unknown. This is because the consequences of such vigilance will be that cubs share out the carcass that their mother captures for them. In fact cubs tend to eat equal amounts: the mean difference in the percent of time cubs ate from kills averaged across the the numbers of carcasses they consumed during observations was $6.4 \% \quad(\mathrm{SD}=6.0, n=37$ watches). According to current theory, mothers' vigilance should therefore be expected to increase with the size of their litter.

If mothers' vigilance is primarily concerned with detecting predators on the other hand, it is a form of 'unshared' parental investment because cubs do not divide up their mother's vigilance but all benefit from it simultaneously. Few instances of predation on cheetah cubs have been witnessed but Fig. 1 shows that the number of cubs killed is not independent of litter size when cubs are 0-3 months old. Therefore any parental behaviour that decreases the risk of predation is expected to increase with litter size (brood loss case of 'unshared investment', Lazarus and Inglis 1986) because a given act by mothers will increase the probability of more cubs reaching reproductive age in large litters.
At 4 months of age, cubs are able to outrun lions and spotted hyaenas (personal observation), and in most cases of predatory attack, it is unlikely that more than one cub would be killed, if at all. The only recorded example of predation at this age supports this: a leopard severely injured only one $9^{1 / 2}$ month old cub out of a litter of 4 , which subsequently died (Burney 1980). If predators take only a single offspring at these ages (or some number independent of litter size), any parental behaviour decreasing the risk of predation is predicted to be independent of litter size during this time (fixed loss case, Lazarus and Inglis 1986) because the benefit of defense to the parent is independent of litter size. Cheetahs therefore provide an excellent opportunity to test parental investment theory as it relates to vigilance.

In this paper, I examine whether cheetah mothers' vigilance constitutes more than one type of parental investment. First, I determine whether mothers' vigilance is associated with differences in the age of their cubs and examine whether mother's hunting and anti-predator behaviour show similar changes. Then I assess the relative importance of mothers' hunting and anti-predator behaviour in determining the extent of their vigilance in different contexts. Finally, I examine the effects of litter size on mothers' vigilance in different circumstances and so provide a detailed test of models of shared and unshared parental investment.

\section{Methods}

\section{Study site and data collection}

Cheetah mothers and their cubs were watched on the long, intermediate, and short grass plains, and plains-woodland border of the Serengeti National Park, Tanzania from July 1980 to December 1983 (see Sinclair 1979 for a general description). Once a family of habituated cheetahs had been located (see Caro and Collins 1986, 1987a, b, for methods), photographs of mother and cubs were taken for subsequent identification, and the number of cubs, their age, and sex was noted. Because exact ages of many litters were unknown, cubs were aged by comparing their shoulder height to that of their mothers as follows: $<1 / 4$ size: $1^{1 / 2}$ months; $>1 / 4$ size: $2^{1 / 2}$ months; $1 / 3$ size: $3^{1 / 2}$ months; $<1 / 2$ size: $4^{1 / 2}$ months; $>1 / 2$ size: $5^{1 / 2}$ months; male cub: $2 / 3$ mother's size, female: $5 / 8$ size: $6^{1 / 2}$ months; male: $3 / 4$, female: ${ }^{2 / 3}$ size: 8 months; male: $7 / 8$, female: $3 / 4$ size: 10 months; male: mother's size or larger, female: $7 / 8$ or full size: $12-18$ months old (fractions are retained here to be a reminder that ages were estimates). This classification corresponded well with cubs whose ages were known from demographic records, and with methods used in a previous study (G. Frame, personal communication).

A family was watched continuously from a vehicle from the time it was located until $19.00 \mathrm{~h}$ using $8 \times 40$ Zeiss binoculars or the naked eye at a distance of $0-150 \mathrm{~m}$. Families were usually relocated the next, and 6 subsequent mornings, thus watches lasted between 1 and 7 days (465-5029 min). Thirty 
three mothers were observed in this way during 54 observation periods ( $2688 \mathrm{~h}$ in total). Some mothers were observed more than once (2-4 times), either because a mother was watched more than once during her cubs' development or because a mother was subsequently observed with a new litter. Only litter sizes up to 4 were watched because the behaviour of more than 5 cheetahs at kills could not be recorded accurately.

\section{Vigilance during the day}

Throughout the whole day, the mother's following activities were noted every $15 \mathrm{~min}$. Observing, defined by body posture, was sitting on backlegs with forelegs vertically supporting body. Resting was lying with flank and hindquarters touching the ground, forequarters could either lie on the ground or be tucked under the animal. The percent of instantaneous samples in both activities was calculated each day and an average taken for all the days in each watch.

During the middle of the day $(09.30-17.00 \mathrm{~h})$ outside the main hunting periods (Schaller 1972), time was given over to recording vigilance of cheetah families in detail. When the mother and cubs had obviously settled down, usually in the shade of a bush or tree, a $3 \mathrm{~h}$ observation period was begun in which behaviour of mothers was recorded every $5 \mathrm{~min}$ on the minute. Vigilance was scored, defined as eyes open and looking around (looking at the ground or a cub were not included). Postures scored were lying flat out (lying prone with head on the ground), lying out (lying prone with head raised), lying alert (lying with flank and hindquarters on the ground but forelegs tucked under body), and sitting up (sitting on backlegs with forelegs vertically supporting the body). If a hunt began which interrupted the rest period, or any individual in the family was recorded as walking for more than two consecutive 5 min scans, the observation period was terminated and only data from previous whole $1 / 2 \mathrm{~h}$ blocks were used in analysis. After a hunt had finished, or when the cheetahs had settled again, a new observtion period was started until 3 undisturbed hours' observation had been made that day. These stringent criteria were used to ensure that cheetahs were only sampled when they were relatively relaxed. The percent of 5 min instantaneous samples in which each mother was vigilant, and in each position, was calculated for each day, (if there were 2, say $1^{1 / 2} \mathrm{~h}$ observation periods on a given day, an average was taken). A mean figure was then calculated for all the days in a watch.

\section{Vigilance at kills}

After cheetahs have made a kill, other predators are quickly attracted to the scene (Schaller 1972; Houston 1974) and this can be a particularly dangerous time for cheetah families (pers obs). Cheetahs usually scan the environment carefully between killing their prey and starting to eat. I therefore recorded the interval between death of the prey and the time the first member of the cheetah family started to eat, and then calculated an average for all the kills made during the watch. Between the time a mother started to feed and the time she finally finished, the number of times she stopped feeding and raised her head to look around the environment was recorded, as were the number of minutes she was not feeding from the carcass. These were expressed as the frequency per minute she looked up from the carcass, and the percent of time she was not feeding and was looking around during this period. Averages of each measure were taken from all the kills made during a watch.

\section{Mother's hunting behaviour}

Hunts were defined as crouching at, stalking, trotting towards, rushing at, or chasing prey (Caro 1986). Hunts that mothers made were expressed as the total number of hunts per hour watched. It was easy to see when a hunt had ended: mothers stopped their advance towards prey after prey had seen them, walked away from prey they had been hunting, failed to catch their quarry at the end of the single chase that characterizes cheetah hunts, or captured their prey (Caro 1987). Time spent in all hunts, whatever their outcome, was also recorded and expressed as a percent of total time mothers were watched.

An estimate was made of the mother's level of hunger by scoring her belly size on a scale from 1 , representing near starvation, to 14 where a mother voluntarily left a kill while there was still meat on it (the animal looked as if it had swallowed a basketball). Cheetahs normally start hunting when their bellies were scale 5 or below. Belly size estimates have been used reliably by other researchers (Bertram 1978; Frame and Frame 1981; Packer 1986) and experienced observers of cheetahs (C. FitzGibbon and myself) almost always score individuals as the same. Moreover, in 16 trials with a relatively inexperienced observer (D. Jefferson), she and I scored cheetahs' belly sizes as the same in 6 trials $(38 \%)$, differed by 1 point in 7 trials $(44 \%)$, and never differed by more than 2 points. Belly sizes taken at the beginning of each day when the mother was first encountered were averaged over all the days of the watch.

\section{Mothers' anti-predator behaviour}

During watches, $I$ recorded all the occasions I saw dangerous predators, lions, leopards and spotted hyaeans from my position near the cheetah family. Included in this list were golden jackals (Canis aureus), black-backed jackals (Canis mesomelas), olive baboons (Papio anubis) and male and female cheetahs all of which could pose a threat to small cubs. Situations in which any of these species stole, or scavenged (see Caro 1982) from the cheetah family's kill after they had left it, were excluded. I noted whether the mother saw the predator at all, and if I could tell, whether she, or one of her cubs, saw it first. Mothers might simply watch the predator pass by, or react to it by leaving (slink off apparently trying to remain hidden, or trot away), crouching (assume a crouching position usually if the predator came to within $40 \mathrm{~m}$ ), or hissing (stand up with back arched and piloerecting and hiss at the predator that was usually less than $5 \mathrm{~m}$ away). Mothers could also react by stalking towards the predator, chasing (rush towards and/or chase the predator; in the case of lions and many spotted hyaenas the cheetah would veer away at the end of its run), or contacting the predator, where it was slapped, usually on the hindquarters. These last 3 patterns were considered as defending the whole litter of cubs. If a mother reacted to a given predator in several of the above ways, only the one that brought the cheetah into closest proximity with the predator (the most dangerous one) was used in the analysis. Care was taken not to rate behaviour patterns on a single scale which might obscure important differences in anti-predator behaviour (Andersson et al. 1980; Robertson and Biermann 1979). Very rare behaviour patterns such as cheetah mothers apparently drawing predators away from hidden cubs (Ammann and Ammann 1984; personal observation) are not presented here.

\section{Analysis}

In case the relatively short watches lasting one day in length were not representative of the cheetahs' behaviour, single day watches were compared with longer watches using one way analysis of variance tests for each measure. Significant differences were found for observing, lying alert, lying flat out, percent of time off the carcass and hunts per hour, so single day watches were dropped from subsequent analyses for these measures. Most measures were normally distributed but if not an 

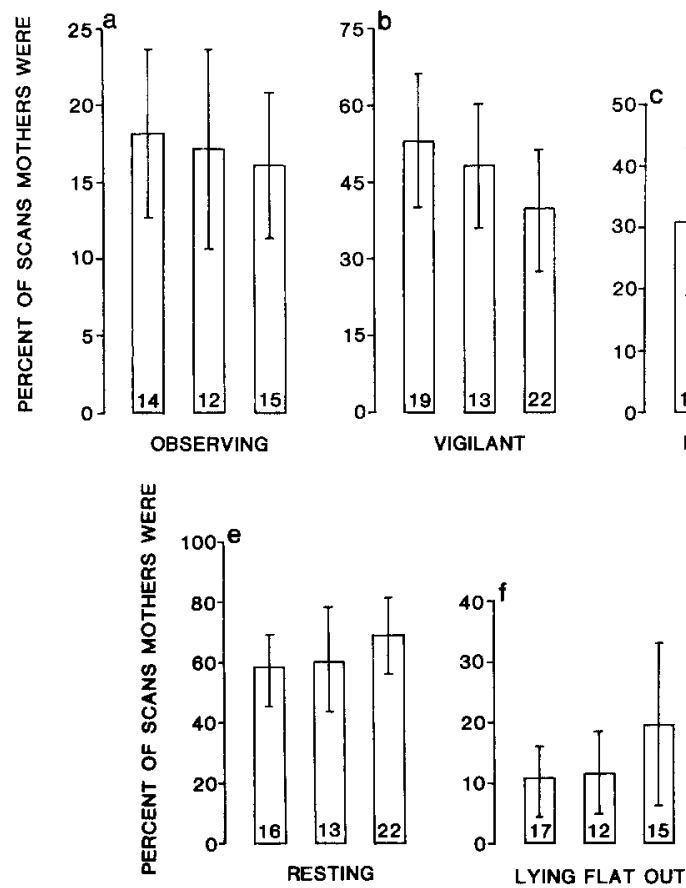
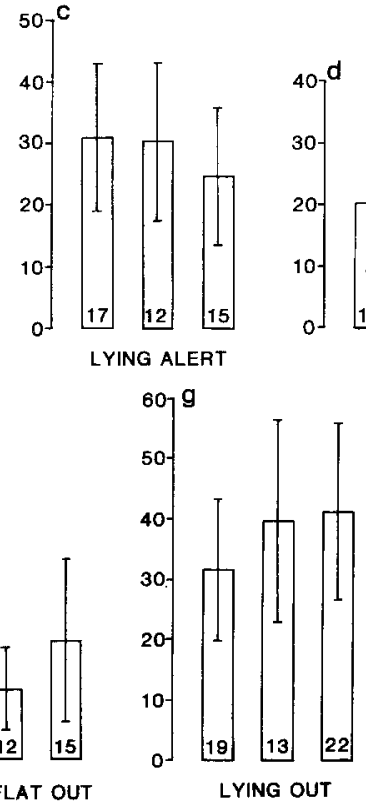

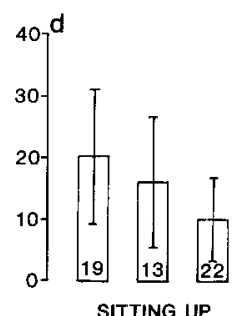

Fig. 2a-g. Measures of mothers' vigilance (top line) and resting behaviour (bottom line) during the day separated by cub age: left $1^{1 / 2}-3^{1 / 2}$ months, centre $4 \frac{1}{2}-6 \frac{1}{2}$ months, right $8-18$ months. Means and standard deviations shown, numbers in histograms denote numbers of watches. Significance values for data shown above, not controlling for the effects of other variables a $F_{2,38}=0.5$, NS, b $F_{2,51}=6.4, P=0.003$, c $F_{2,41}=1.3$, NS, d $F_{2,51}=6.1, P=0.004$, e $F_{2,48}=3.8$, NS, f $F_{2,41}=4.1, P=0.024, \mathrm{~g} F_{2,51}=2.6$, $P=0.085$; see also text arcsine (frequency mothers looked up from the carcass, average belly size/10) or $\log 10$ transformation (lying flat out, pause before eating, percent of time spent hunting, percent of occasions mothers actively reacted to predators) was applied to the data. If the data could not be normalized easily, Spearman rank order correlation coefficients were used.

To circumvent the possibility that mothers who were represented more than once in the sample were biasing results, because they were particularly vigilant or particularly frequent hunters for example, watches were coded by mother and individual differences between mothers tested for on each variable. If individual differences were found $(P$-value $<0.1)$, this independent variable was retained in all the subsequent ANOVAS quoted for that dependent variable. As with cub age, sex, and litter size, mother effects were dropped from the analysis if they were not found to be significant; thus statistical values quoted here control for these confounding variables, unless stated.

ANOVAS were used to compare measures of vigilance with hunting and anti-predator behaviour, but in cases where all the categorical variables could be dropped because of non-significance, Pearson correlation or partial correlation coefficients were used in the analysis (Table 1). As litters of 1 and 4 cubs were watched less often than litters of other sizes, data from litters of 1 and 2 cubs, and 3 and 4 cubs, were lumped together in litter size comparisons. If there were no significant effects of other variables using ANOVAS, $T$-tests were used to compare the two groups.

\section{Results}

\section{The influence of cubs' age on mothers' vigilance}

Figure 2 shows that mothers' vigilance declined as their cubs grew older. When significant effects of litter size, sex and differences between mothers were taken into account, the percent of time that mothers observed their surroundings throughout the day decreased significantly with cub age $\left(F_{1,14}=8.5, P=0.011\right)$, as did the percent of time that mothers were vigilant in the middle of the day $\left(F_{1,49}=17.4, P<0.0005\right)$. The percent of time mothers spent lying alert (NS) and sitting up (NS) declined as cubs grew older. There was a concommitant increase in the percent of time mothers rested throughout the day $\left(F_{1,18}=2.9, P=0.107\right)$, and they spent a greater percent of time lying flat out (NS) and lying out (NS) as cubs grew older.

At kills, mothers paused longer before starting to eat $\left(F_{8,34}=3.3, P=0.007, F i g .3\right)$ and spent a greater percent of time off the carcass when their cubs were young $\left(F_{8,29}=2.4, P=0.038\right)$. However, there was no change in the frequency with which they looked up from the carcass wth cub age (NS) when other variables were taken into account.

\section{Changes in mothers' hunting and anti-predator behaviour with cub age}

Two factors are likely to be responsible for the changes in vigilance associated with cub age: the degree to which mothers look up to catch sight of prey and the degree to which they look up to detect predators that are potentially dangerous to their cubs.

Figure 4 shows that the percent of time that mothers spent hunting declined significantly with the age of their cubs (controlling for litter size: $F_{1,49}=5.4, P=0.024$ ), and although the number 

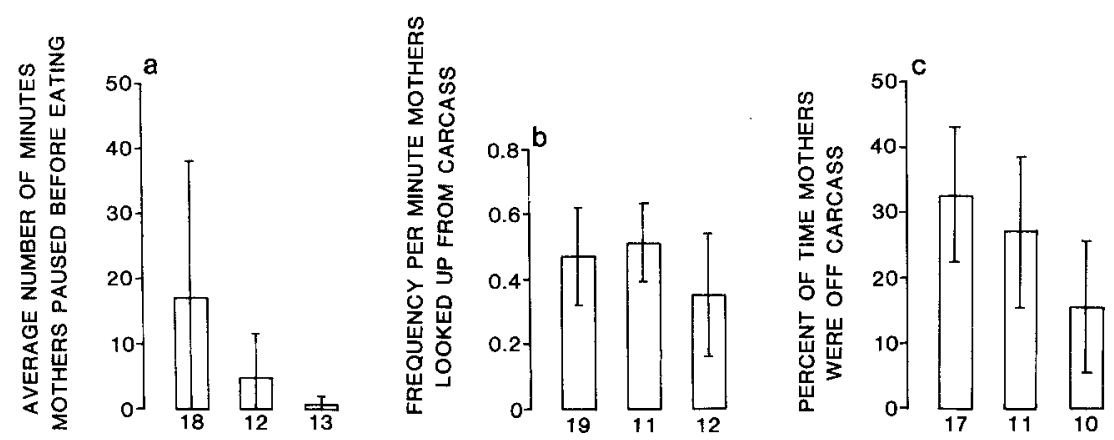

Fig. 3a-c. Measures of mothers' vigilance at kills separated by cub age. Left $1^{1 / 2}$ $3^{1 / 2}$ months, centre $4^{1 / 2}-6^{1 / 2}$ months, right 8-18 months. Means and standard deviations shown, numbers below histograms denote numbers of watches. Significance values for data shown above, not controlling for the effects of other variables a $F_{2,40}=10.4, P<0.0005$, b $F_{2,39}=3.1, P=0.058$, c $F_{2,35}=8.0, P=$ 0.001 ; see also text
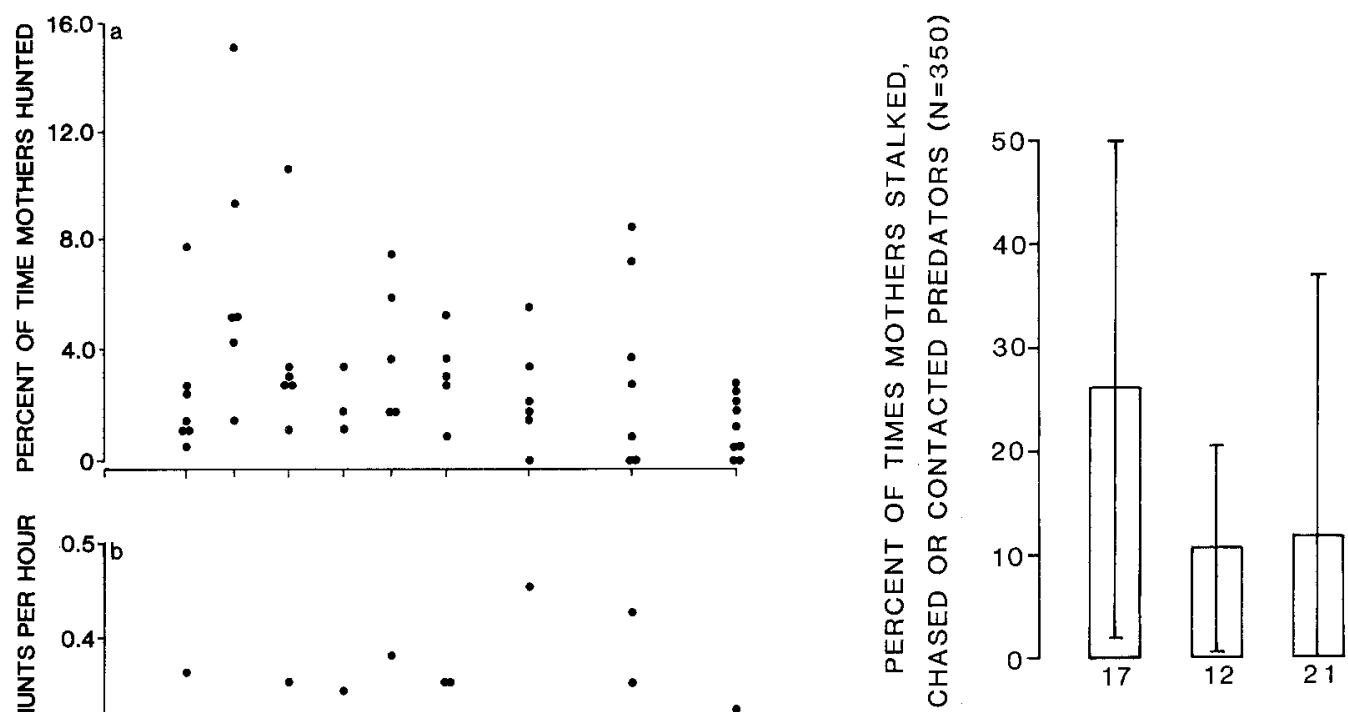

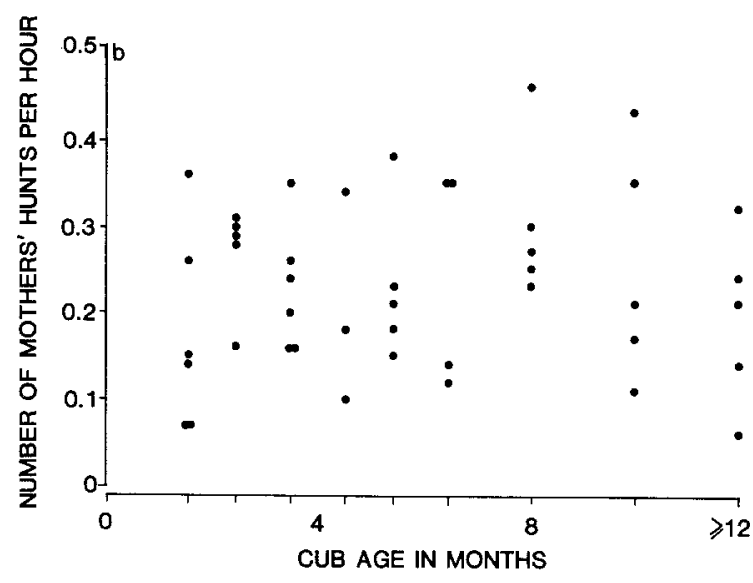

Fig. 4 a, b. Measures of mothers' hunting separated by cub age. Significance values not controlling for the effects of other variables. a $n=54, r=-0.315, P=0.02$ using logged data, $y=4.542+$ $0.236 x, \mathbf{b} n=44, r=0.082$, NS using raw data, $y=0.219+0.002 x$

of hunts per hour did not decrease (NS), there was a drop after cubs reached 8 months of age. These changes corresponded, to some extent, with an increase in cub hunting activity with age (percent of hunts that cubs initiated as compared to their mother with age, $n=52, r_{\mathrm{s}}=0.749, P<$ 0.0005 ; percent of time that cubs hunted alone without their mother, $n=52, r_{\mathrm{s}}=0.533, P<0.0005$; number of hunts that cubs made per hour in which the mother did not participate, $n=54, r_{\mathrm{s}}=0.556$, $P<0.0005$; and percent of successful hunts where prey was actually caught by the cubs alone, $n=45$, $r_{\mathrm{s}}=0.440, P=0.002$ ). Nevertheless, measures of
Fig. 5. Mean percent of times (and SDs) that 31 different mothers reacted to 350 threats in different ways taken from 50 different watches; see key to Fig. 3, and text for significance level

mothers' hunting behaviour were not significantly negatively correlated with these measures of cubs' hunting behaviour. Even old cubs were poor hunters; mothers captured nearly all the prey during the period families were watched (167 out of 178 successful hunts, $93.8 \%$ ).

Of the total of 385 potentially dangerous situations that I witnessed, mothers treated the 350 threats that they noticed $(90.9 \%)$ differently according to cub age (cub age had no influence on the frequency with which cheetah families faced danger $(n=50, r=0.122$, NS)). The percent of occasions mothers reacted to dangerous predators, instead of just watching them, was unaffected by cub age (NS) but mothers defended their cubs more often when cubs were young $\left(F_{2,47}=3.7, P=\right.$ 0.32, Fig. 5).

The decline in both mothers' hunting and antipredator behaviour with cub age, which parallel the changes in vigilance, suggest that vigilance may be associated with both of these forms of behaviour. 
Table 1. Associations between measures of mothers' vigilance and measures of hunting and anti-predator behaviour

\begin{tabular}{|c|c|c|c|}
\hline \multicolumn{2}{|l|}{ Hunting } & \multicolumn{2}{|c|}{ Anti-predator behaviour } \\
\hline $\begin{array}{l}\text { Percent of } \\
\text { time spent } \\
\text { hunting }\end{array}$ & $\begin{array}{l}\text { Number of } \\
\text { hunts/hour }\end{array}$ & $\begin{array}{l}\text { Percent of } \\
\text { instances } \\
\text { mother reacted }\end{array}$ & $\begin{array}{l}\text { Percent of } \\
\text { instances cubs } \\
\text { defended }\end{array}$ \\
\hline \multicolumn{4}{|c|}{ Vigilance during the day } \\
\hline \multicolumn{4}{|c|}{ Percent of time observing } \\
\hline $\begin{array}{l}r=0.589 \\
n=39 \\
P<0.0005\end{array}$ & $\begin{array}{l}r=0.439 \\
n=39 \\
P<0.005\end{array}$ & $\begin{array}{l}r=0.211 \\
n=36, \mathrm{NS}\end{array}$ & $\begin{array}{l}r=0.220 \\
n=36, \mathrm{NS}\end{array}$ \\
\hline \multicolumn{4}{|c|}{ Percent of time vigilant } \\
\hline $\begin{array}{l}F_{1,45}=27.3 \\
P<0.0005\end{array}$ & $\begin{array}{l}F_{1,38}=7.2 \\
P=0.011\end{array}$ & $\begin{array}{l}F_{1,37}=0.7 \\
\mathrm{NS}\end{array}$ & $\begin{array}{l}F_{1,45}=12.5 \\
P=0.001^{\mathrm{a}}\end{array}$ \\
\hline \multicolumn{4}{|c|}{ Percent of time sitting up } \\
\hline $\begin{array}{l}F_{1,46}=6.8 \\
P=0.012\end{array}$ & $\begin{array}{l}F_{1,13}=2.1 \\
\mathrm{NS}\end{array}$ & $\begin{array}{l}F_{1,45}=0.1 \\
\text { NS }\end{array}$ & $\begin{array}{l}F_{1,45}=0.0 \\
\mathrm{NS}\end{array}$ \\
\hline \multicolumn{4}{|c|}{ Vigilance at kills } \\
\hline \multicolumn{4}{|c|}{ Frequency of looking up from the carcass } \\
\hline $\begin{array}{l}F_{1,35}=1.0 \\
\mathrm{NS}\end{array}$ & $\begin{array}{l}r=-0.171 \\
\text { NS }\end{array}$ & $\begin{array}{l}F_{1,35}=1.6 \\
\mathrm{NS}\end{array}$ & $\begin{array}{l}r=0.386 \\
P=0.015\end{array}$ \\
\hline
\end{tabular}

a Mothers were significantly less likely to defend cubs the more vigilant they were

\section{Vigilance, hunting, and anti-predator behaviour}

Table 1 shows that measures of mothers' vigilance during the day were significantly positively associated with measures of hunting but not with measures of anti-predator behaviour, after the effects of different mothers, cub age, and litter size had been taken into account. The percent of time that mothers spent observing their environment throughout the day was significantly associated with the percent of time mothers hunted and the rate at which they hunted per hour. Vigilance in the middle of the day was also associated with these two measures of hunting. Lying alert was not significantly associated with hunting or antipredator behaviour (all 4 comparisons NS), but sitting up in the middle of the day was with the percent of time mothers hunted. None of these 4 measures of vigilance were significantly associated with the 2 measures of anti-predator behaviour, nor were they when analysis was restricted to the first $3^{1 / 2}$ months of life when cubs are particularly susceptible to predation.

In contrast, the 3 measures of vigilance at kills were not significantly related to the 2 measures of hunting (all NS) but were associated with antipredator behaviour: the frequency with which mothers looked up from the carcass was significantly positively correlated with the percent of oc-
Table 2. Spearman rank order correlation coefficients of measures of mothers' vigilance correlated with the percent of occasions that mothers were known to sight predators before their cubs did

\begin{tabular}{|c|c|c|c|}
\hline Behaviour & No. watches & $s r_{\mathrm{s}}$ value & $P$ value \\
\hline$\%$ time observing & 29 & 0.150 & 0.436 \\
\hline$\%$ time vigilant & 37 & 0.306 & 0.065 \\
\hline$\%$ time lying alert & 31 & -0.096 & 0.607 \\
\hline$\%$ time sitting up & 37 & 0.409 & 0.012 \\
\hline Pause before eating & 33 & 0.264 & 0.138 \\
\hline Frequency look up & 32 & 0.309 & 0.085 \\
\hline$\%$ time off carcass & 29 & 0.387 & 0.038 \\
\hline
\end{tabular}

casions they defended their cubs in situations away from kills (other 4 comparisons not shown, all NS). Moreover, the length of time mothers waited before eating was somewhat associated with defense of cubs when analysis was restricted to the first $3^{1 / 2}$ critical months $(n=16, r=0.433, P=0.094)$. Finally, Table 2 shows that the 3 measures of vigilance at kills were good predictors of the percent of occasions mothers were known to notice sources of danger before their cubs did. These conclusions are further supported by independent data drawn from two examples of cub predation. Table 3 contrasts the mean levels of mothers' vigilance in two situations where cubs were killed and eaten by lionesses while a watch was in progress, and two situations in which this did not occur. The limited data show that all 3 measures of vigilance at kills were enhanced in days after the attack by lions, but of the measures of vigilance during the day, only lying alert, and in one case percent of time observing, increased after the encounters. Lying alert appeared to be a measure of unease on the part of the mother.

Given that mother's vigilance during the day was associated with hunting, while her vigilance at kills was associated with anti-predator behaviour, I now examine whether the two kinds of vigilance vary with litter size in different ways as predicted by Lazarus and Inglis (1986).

\section{Effects of litter size on hunting and vigilance during the day}

Mothers' hunting increased with litter size but not significantly, as measured by the percent of time hunting (NS), and by the number of hunts made per hour (NS). However, mothers did spend more time hunting with larger litters (of 3 and 4 cubs) when cubs were young $\left(1^{1} / 2-3^{1} / 2\right.$ months old: $\bar{X}=$ $\left.5.12,1.91 \mathrm{mins} / \mathrm{hr}, t_{13,6}=2.06, P=0.055\right)$; and mothers' average belly sizes were lower the more 
Table 3. Changes in measures of vigilance in litters in which cubs died during a watch. Mean values before and after a death are given calculated from the number of days watched. In the $2 \frac{1}{2}$ month old litter there was an 8 day gap between first and second parts of the watch

\begin{tabular}{|c|c|c|c|c|c|c|c|}
\hline \multirow{3}{*}{$\begin{array}{l}\text { No. } \\
\text { days } \\
\text { watch }\end{array}$} & \multicolumn{4}{|c|}{ Vigilance during the day } & \multicolumn{3}{|c|}{ Vigilance at kills } \\
\hline & \multicolumn{4}{|l|}{$\%$ time } & \multirow{2}{*}{$\begin{array}{l}\text { Pause to eat } \\
\text { (mins) }\end{array}$} & \multirow{2}{*}{$\begin{array}{l}\text { Freq look up } \\
\text { per min }\end{array}$} & \multirow{2}{*}{$\begin{array}{l}\% \text { time off } \\
\text { prey }\end{array}$} \\
\hline & Observe & Vigilant & Alert & Sit up & & & \\
\hline \multicolumn{8}{|c|}{1 of 3 cubs killed by lion $(1 / 2$ months old $)$} \\
\hline 2 & 21.1 & 58.2 & 39.1 & 17.4 & 29.5 & 0.50 & 24.5 \\
\hline 3 & 18.5 & 52.5 & 46.2 & 10.0 & 17.1 & 0.82 & 37.7 \\
\hline \multicolumn{8}{|c|}{2 of 4 cubs killed by lion $(1 / 2$ months old $)$} \\
\hline 3 & 16.3 & 54.7 & 18.5 & 28.9 & 8.8 & 0.51 & 26.5 \\
\hline 4 & 21.0 & 53.2 & 26.8 & 17.9 & 29.3 & 0.66 & 25.8 \\
\hline \multicolumn{8}{|c|}{1 of 3 cubs died from disease ( 8 months old) } \\
\hline 4 & 3.8 & 53.3 & 25.7 & 8.4 & 0.3 & 0.14 & 4.7 \\
\hline 3 & 2.9 & 40.3 & 13.3 & 0.7 & 0 & - & - \\
\hline \multicolumn{8}{|c|}{1 of 4 cubs disappeared for reasons unknown ( $2^{1 / 2}$ months old) } \\
\hline 3 & - & 56.8 & 42.1 & 20.6 & 32.1 & 0.65 & 43.3 \\
\hline 1 & 25.0 & 43.2 & 43.2 & 24.3 & - & - & - \\
\hline
\end{tabular}

cubs they had in their charge $(\bar{X}=5.17,5.31$, $\left.F_{1,20}=10.4, P=0.004\right)$.

Similary, although mothers of larger litters did not observe their surroundings more than mothers of smaller litters (NS), they spent significantly more time observing with litters of 3 or 4 cubs than if they had litters of 1 or 2 at young cub ages $\left(t_{9,5}=2.82, P=0.015\right.$, Fig. $\left.6 \mathrm{a}\right)$, although not at older ages (6b, NS; $6 c$, NS). Again, mothers of larger litters were not significantly more vigilant than mothers of small litters across all ages (NS) but there was an indication that they were more vigilant when cubs were young $\left(t_{13.6}=1.85, P=\right.$ 0.082 , Fig. $6 \mathrm{~d}$ ) but not at older ages $(6 \mathrm{e}, \mathrm{NS} ; 6 \mathrm{f}$, NS). Finally, although there was no overall effect of litter size on the percent of scans mothers lay alert (NS) or sat up (NS), mothers of larger litters spent more time sitting up in the middle of the day than mothers of small litters in two of the age groups $\left(11^{1} / 2^{-}-3^{1} / 2\right.$ months: $\bar{X}=23.8 \%, 12.3 \%$, $t_{13,6}=2.40, \quad P=0.028 ; 4^{1} / 2^{-}-6^{1} / 2$ months: $\bar{X}=$ $10.7 \%, 20.4 \%, t_{6,7}=-1.88, P=0.099$, using separate estimates of variance; $8-18$ months: $\bar{X}=$ $15.1 \%, 8.4 \%, t_{5,17}=2.07, P=0.052$ ).

\section{Effects of litter size}

\section{on anti-predator behaviour and vigilance at kills}

The percent of occasions mothers reacted to dangerous predators was significantly greater in larger litters $\left(\bar{X}=56.3 \%, 38.2 \%, t_{22,28}=2.34, P=0.024\right)$ as was the percent of occasions they defended their

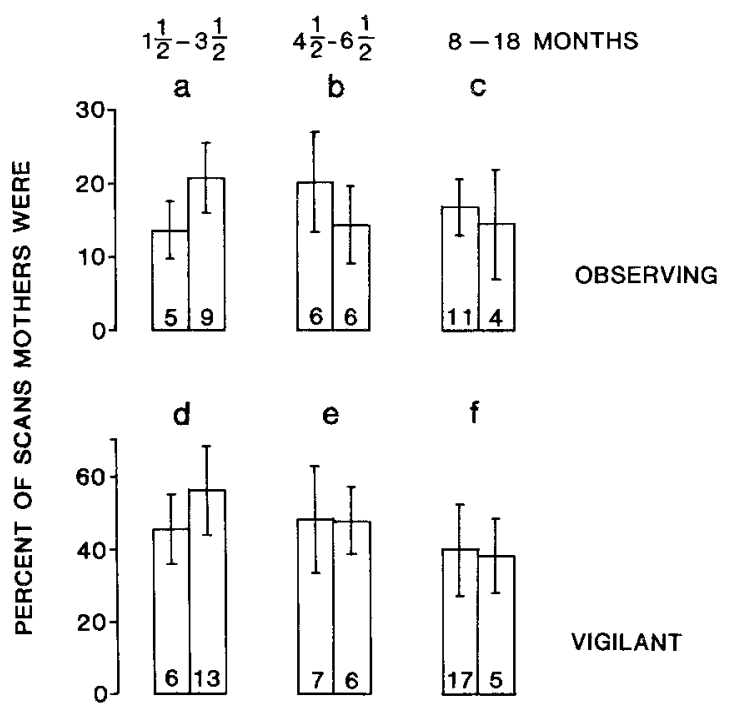

Fig. 6a-f. Measures of mothers' vigilance during the day separated by cub age and litter size; lefthand histograms denote small litters of 1 and 2 cubs, righthand histograms large litters of 3 and 4 cubs. Means and standard deviations shown; numbers in histograms denote numbers of watches; see text for significance levels

cubs $\left(\bar{X}=28.3 \%, \quad 7.1 \%, \quad F_{1,47}=4.4, \quad P=0.042\right)$. Separating anti-predator behaviour by cub age, mothers with large litters of $1 \frac{1}{2} 2^{-3} 3^{1 / 2}$ month old cubs did not react to predators more often than mothers of small litters (NS) but there was a tendency to defend them more often $(\bar{X}=31.4 \%$, $\left.13.4 \%, F_{1,14}=3.1, P=0.103\right)$. Litter size had few significant effects on mothers' reaction to preda- 
tors (NS) or defense of cubs (NS, NS) in the two older age groups, except that mothers of larger litters reacted to threats more often than those with small litters $\left(\bar{X}=68.3 \%, 35.3 \%, t_{5,16}=2.37, P=\right.$ 0.028 ) when cubs were $8-18$ months old.

In contrast, there was no evidence to show that mothers of larger litters waited longer before they started to eat a kill (NS), spent longer off the carcass (NS) or looked up more often (NS) than mothers of smaller litters, nor could any significant differences be found when the data were separated by cub age (all 9 comparisons NS).

\section{Discussion}

\section{Vigilance during the day}

Results in Table 1 show that the percent of time mothers observed their environment, and their vigilance in the middle of the day was related to time spent hunting and the number of hunts made per hour, but showed little association with measures of anti-predator behaviour. This suggests that the decline in these measures of vigilance as cubs grew older occurred because mothers were less active in hunting, and Fig. 4 showed time spent hunting did indeed decline with cub age. Similarly, the increased vigilance shown by mothers with larger litters (for $1^{1} / 2-3^{1} / 2$ month old cubs) was probably associated with the somewhat greater amount of time these mothers hunted. This was because prey was usually first located visually, at some distance away, before a hunt commenced, except for hares (Lepus crawshayi and L. capensis) and a few other prey which were scared up by walking cheetahs.

The decline in mothers' hunting with cub age probably occurred because lactation imposed a heavy energetic burden, and mothers required a regular food intake to sustain a milk supply before weaning at around 14 weeks of age (pers obs, see also Caro et al. in press, for method of estimating how many kilograms of edible meat mothers ate per day). This is supported by data showing that mothers of larger litters spent more time hunting when their cubs were young, and had significantly lower average belly sizes with larger litters. Increases in cub hunting activity were insufficient to account for the decline in mothers' hunting.

In short, differences in measures of vigilance off kills, and to some extent mothers' posture, associated with both cub age and litter size when cubs were young, could be accounted for by similar differences in mothers' hunting behaviour. As maternal hunting constitutes a form of shared parental investment, the vigilance necessary to locate prey, except hares which accounted for only $9.2 \%$ of mothers' hunting attempts $(n=349)$, can also be regarded as a form of shared investment. As predicted by Lazarus and Inglis (1986), this form of vigilance does increase with litter size. Whether vigilance increases in direct proportion to the number of cub in a litter is beyond the scope of this paper because large litters of 5 and 6 , in which investment per capita might start to decline, were not observed in this study.

\section{Vigilance at kills}

In contrast to vigilance during the day, maternal vigilance at kills appeared to be unrelated to measures of hunting behaviour. Since mothers had successfully captured prey, they were unlikely to be on the look out for additional prey. Instead, the rate at which mothers looked up from the carcass was associated with the percent of instances they defended their cubs; and the length of time they waited before eating was also associated with this measure in young litters.

The correlation between vigilance at kills and anti-predator behaviour is broadly supported by the fact that both the pause before eating and the percent of time mothers spent off the carcass (Fig. 3), and defense of cubs (Fig. 5) all declined with cub age. Although adult cheetahs are killed by lions and leopards (Guggisberg 1962; Graham and Parker 1965; Pienaar 1969; Kuenkel 1978; Burney and Burney 1979; A. Root, personal communication), behaviour used to thwart personal attack is not expected to change with cub age. Rather, such maternal anti-predator behaviour might be expected to follow changes in the high cub mortality (Nairobi, 43\%, McLaughlin 1970; Kruger, 'about 50\%', Pienaar 1969; Serengeti National Parks, 'about 50\%', Schaller 1972). In particular, 0-3 month old cubs are killed by lions (Burney 1980; Frame and Frame 1981; Ammann and Ammann 1984; this study), by spotted hyaenas (Burney 1980; Eaton 1974), and probably by jackals (Ammann and Ammann 1984), in part because they cannot outrun these predators (personal observation). Moreover, two cases of male cheetahs fighting with mothers' of newborn cubs, and the subsequent disappearance of cubs in one of these cases, led Burney (1980) to suspect that cheetah males may commit infanticide, and there are theoretical reasons for believing that males could enhance their reproductive success in this way if bereaved mothers ranged little after their cubs were killed and before coming into oestrus (Caro and Collins 1987a; see also Packer and Pusey 1984). 
Furthermore, young cubs appeared to have difficulty in recognising what objects were dangerous and what objects were harmless. Frame and Frame (1981) reported 5 or 6-week old cubs running towards a lioness, and in this study, instances in which cubs responded to objects that were not dangerous such as a kori bustard (Ardeotis kori) or bat-eared fox (Otocyon megalotis) by behaving defensively (hissing at it or running away) all occurred when cubs were $3^{1 / 2}$ months old or less. This period corresponds precisely to the time that cubs have their peculiar natal coat, which has a light grey woolly mantle but is black on the ventral surface, and suggests that its function is for camouflage against terrestial predators and aerial predators such as martial eagles (Polemaetus bellicosus) or crowned hawk eagles (Stephanoaetus coronatus) (Maugham 1914). Several times I saw small cubs scattering and hiding so effectively that they could not be found by lions searching for them (see also Ammann and Ammann 1984). However, cheetahs' natal coats could confer additional benefits through more efficient temperature regulation (Frame and Frame 1981) or protection against wind and sun (Cade 1965), but there is little support for the suggestions that it reduces attacks by conspecifics (Kingdon 1977) or that it mimics the pelage of the ratel (Mellivora capensis) (Pocock 1932). For all these reasons, mothers are expected to be on the look out for threats to their cubs.

Prior to cubs reaching 4 months of age, mothers lose more cubs to predators the larger is the size of their litter (Fig. 1). Because predation risk is not independent of litter size, anti-predator behaviour, and the vigilance at kills associated with it, are predicted to increase with litter size. Yet mothers in charge of young cubs were no more vigilant at kills if they had large litters. While at first sight this finding runs contrary to the hypothesis, closer examination suggests it is precisely what might be expected. When predators are attracted to cheetahs' kills, by the commotion caused by fleeing gazelles, the dust thrown up in a chase, or the place to which vultures are descending, they invariably steal the kill if they find it (which requires no effort in capture) rather than attempt to kill cheetahs (as in all of the 20 kills stolen by spotted hyaenas and 2 stolen by lions out of the 193 mothers' kills where I witnessed entire carcass consumption; see O'Brien et al. 1986 for an inflated figure). If competitors are trying to maximize food intake, they are extremely unlikely to pursue fleeing cubs, a small amount of meat compared to what might be on the carcass, and in most cases cubs will escape. Even if a cub was surprised and killed, the competitor would be likely to turn its attention quickly to the carcass, (none of the quoted examples of cub predation occurred at kills). Thus risk of predation at carcasses is almost certainly independent of litter size (because the carcass is there) and parental investment is not expected to increase with litter size in these situations whatever the age of the cubs (fixed loss case of unshared parental investment). The data on vigilance at kills strongly support this interpretation: at no age did mothers' vigilance increase with litter size.

Nevertheless, interpreting vigilance at kills as a form of anti-predator behaviour is not entirely without problems. The best measure of maternal vigilance at kills, namely the rate at which mothers looked up, did not decline appreciably until cubs were 8 months old (Fig. 3) while defense of cubs was affected by cub age. This suggested that the rate at which mothers looked up was not solely for the purpose of spotting predators but might also be for securing additional prey. Occasional instances of mothers making multiple kills were observed, often but not always, a mother Thomson's gazelle (Gazelle thomsoni) and her fawn. The association between pause before eating and active defense of cubs at young ages is interesting because, after cubs were $3^{1} / 2$ months old, such pauses were often curtailed by cubs starting to eat the carcass before their mother did. Before this age they might stay behind, hidden, during the hunt; might not notice the dead prey; apparently not realise the prey was edible; or attempt to nurse while the mother paused before eating. Such pauses by the mother, as recorded here, may therefore be meaningful only when the cubs were young, and this is when an association was found. However, pauses may, in part, have been a consequence mothers recovering from exhausting hunts (see Taylor and Rowntree 1973); mean time spent in successful hunts was significantly correlated with the mean length of such pauses $\left(n=39, r_{\mathrm{s}}=0.310\right.$, $P=0.055$ ). Last, the lack of association between the percent of time mothers spent off the carcass and anti-predator behaviour suggests that this might have been a weak measure of vigilance. Occasionally, cheetahs might look up from the carcass, scan the surroundings, and then move off $1 \mathrm{~m}$ to rest for several minutes before resuming eating later. So this measure could, in part, have also reflected temporary satiation or even competition with cubs over food.

At young ages, mothers of larger litters were somewhat more assiduous in active defense of their cubs against predators than those with smaller lit- 
ters, as predicted by Lararus and Inglis's model (brood loss case). At older ages, when mobile cubs can escape predators and the number of cubs killed is independent of litter size, anti-predator behaviour is not expected to increase with litter size (fixed loss case). Again, the data support this: aside from mothers of larger litters reacting more frequently to predators at 8-18 months, there were no significant differences in the percent of occasions mothers responded to threats according to litter size at intermediate or old cub ages. The above exception is readily explained: large cubs stalked and chased predators, especially jackals, with increasing frequency as they grew older, and mothers would often follow their cubs and join in these 'games'. It was my impression that once a large litter of 3 or 4 cubs had all left their resting place in pursuit of a jackal, their mother would invariably follow and take part, perhaps so as not to lose contact with her offspring. It is the increase in stalking and chasing by families, no longer a sensitive measures of maternal anti-predator behaviour, that accounts for mothers' reactions to predators at this time.

Acknowledgements. I thank the Government of Tanzania for permission to conduct research, Professor Karim Hirji, Acting Directors of the Serengeti Wildlife Research Institute, and Tanzania National Parks' authorities for help and cooperation during the study. I was supported by a Royal Society Scientific Investigations grant, the Max-Planck Institut für Verhaltensphysiologie, and the Department of Zoology and Sub-Department of Animal Behaviour, Cambridge University. I am grateful to Monique Borgerhoff Mulder, Peter Hetz, Andrew Hill, Sue Praill, and Alan and Joan Root for logistical support; to Donna Jefferson for help in the field; to Pat Bateson for transporting data around the world; and to Monique Borgerhoff Mulder for tuition in computing. Special thanks go to Steve Albon for statistical advice; both he and John Lazarus made helpful comments on the manuscript. This is S.R.I. contribution No 350 .

\section{References}

Ammann K, Ammann K (1984) Cheetah. Camerapix Publ Int, Nairobi

Andersson M, Wiklund CG, Rundren H (1980) Parental defense of offspring: a model and an example. Anim Behav $28: 536-542$

Bertram B (1978) Pride of lions. Dent \& Sons, London

Bertram BCR (1980) Vigilance and group size in ostriches. Anim Behav 28:278-286

Best GA, Edmond-Blanc F, Witting RC, Raw WG (1962) Rowland Ward's Records of Big Game XIth Edition (Africa). Rowland War Ltd, London

Burney DA (1980) The effects of human activities on cheetahs (Acinonyx jubatus Schr.) in the Mara Region of Kenya. Msc Thesis, University of Nairobi

Burney D, Burney L (1979) Cheetah and man. Swara Magasine $2(3): 28-32$
Cade R (1965) Cheetah just tolerate humans. Africana 2(4):3335

Caro TM (1982) A record of cheetah scavenging in the Serengeti. Afr J Ecol 20:213-214

Caro TM (1986) The functions of stotting in Thomson's gazelles: some tests of the predictions. Anim Behav $34: 663-684$

Caro TM (1987) Indirect costs of play: cheetah cubs reduce maternal hunting success. Anim Behav 35:295-297

Caro TM, Collins DA (1986) Male cheetahs of the Serengeti. Nat Geogr Res 2:75-86

Caro TM, Collins DA (1987a) Ecological characteristics of territories of male cheetahs (Acinonyx jubatus). J Zool 211:89105

Caro TM, Collins DA (1987b) Male cheetah social organization and territoriality. Ethology 74:52-64

Caro TM, Holt ME, FitzGibbon CD, Bush M, Hawkey CM, Kock RA (1987) Health of adult free-living cheetahs. J Zool (in press)

Dunbar RIM, Dunbar EP (1980) The pairbond in klipspringer. Anim Behav 28:219-229

Eaton RL (1970) Group interactions, spacing and territoriality in cheetahs. Z Tierpsychol 27:481-491

Eaton RL (1974) The Cheetah: The biology, ecology, and behaviour of an endangered species. Van Nostrand Reinhold, New York

Frame G, Frame L (1976) The vulnerable cheetah. Expedition VI (6): $40-46$

Frame GW, Frame LH (1977) Serengeti cheetah. Wildlife News 12(3):2-6

Frame G, Frame L (1981) Swift enduring: Cheetahs and wild dogs of the Serengeti. Dutton, New York

Graham AD, Parker ISC (1965) East African Wild Life Society cheetah survey, report by Wildlife Services. East African Wildlife Society, $25 \mathrm{p}$ mimeo

Guggisberg CAW (1962) Simba, the life of the lion. Bailey Bros. \& Swinfen, London

Houston DC (1974) Food searching behaviour in griffon vultures. E Afr Wildl J 12:63-77

Iwago $M$ (1986) The Serengeti: A portfolio. Nat Geog 169(5):560-583

Kingdon J (1977) East african mammals: An atlas of evolution in Africa. Vol. III. Pt. A (Carnivores). Academic Press, New York

Kruuk H (1972) The spotted hyaeana. University of Chicago Press, Chicago

Kuenkel R (1978) Cheetahs - swift cats of the Serengeti. Geo Magazine 1:94-110

Lamprecht J (1978) The relationship between food competition and foraging group size in some larger carnivores. Z Tierpsychol 46:337-43

Lazarus J, Inglis IR (1978) The breeding behaviour of the pinkfooted goose: parental care and vigilant behaviour the fledging period. Behaviour 65:62-88

Lazarus J, Inglis IR (1986) Shared and unshared parental investment, parent-offspring conflict and brood size. Anim Behav 34:1791-1804

Lienhardt G (1961) Divinity and experience: The religion of the dinka. Clarendon Press, Oxford

Leyhausen P (1979) Cat behavior: The predatory and social behavior of domestic and wild cats. (Transl by BA Tonkin). Garland, New York

Maugham RCF (1914) Wild game in Zambezia. Charles Scribner's sons, New York

McLaughlin RT (1970) Aspects of the biology of cheetahs Acinonyx jubatus (Schreber) in Nairobi National Park. Msc thesis, University of Nairobi 
McVittie R (1979) Changes in the social behaviour of South West African cheetah. Madoqua 11:171-184

Myers N (1975) The cheetah (Acinonyx jubatus) in Africa. IUCN Monograph No. 4. IUCN, Morges, Switzerland

O'Brien SJ, Wildt DE, Bush M (1986) The cheetah in genetic peril. Sci Am 254(5):68-76

Packer C (1986) The ecology of sociality in felids. In: Rubenstein DI, Wrangham RW (eds) Ecological aspects of social evolution. Princeton University Press, Princeton, pp 429451

Packer C, Pusey AE (1982) Cooperation and competition within coalitions of male lions: kin selection or game theory? Nature 296:740-742

Packer C, Pusey AE (1984) Infanticide in carnivores. In: Hausfater G, Hrdy SB (eds) Infanticide: comparative and evolutionary perspectives. Aldine, New York, pp 3142
Pienaar U de (1969) Predator-prey relations amongst the larger mammals of Kruger National Park. Koedoe 12:108-176

Pocock RI (1932) Exhibition of a young cheetah skin. Proc Zool Soc Lond 844-845

Robertson RJ, Biermann GC (1979) Parental investment strategies determined by expected benefits. $Z$ Tierpsychol $50: 124-128$

Schaller GB (1967) The deer and the tiger. University of Chicago Press, Chicago

Schaller GB (1972) The Serengeti Lion. University of Chicago Press, Chicago

Sinclair ARE (1979) The Serengeti environment. In: Sinclair ARE, Norton-Griffiths M (eds) Serengeti: dynamics an ecosystem. University of Chicago Press, Chicago, pp 31-45

Taylor RC, Rowntree VJ (1973) Temperature regulation and heat balance in running cheetahs: a strategy for sprinters? Am J Physiol 224:848-854 